\title{
OPTIMISING INVESTMENT PERFORMANCE THROUGH INTERNATIONAL DIVERSIFICATION
}

\author{
JOHAN SWART \\ Department of Mathematics and Applied Mathematics \\ University of Natal \\ Pietermaritzburg \\ South Africa
}

\begin{abstract}
International portfolio diversification is often advocated as a way of enhancing portfolio performance particularly through the reduction of portfolio risk. Portfolio managers in Europe have for decades routinely invested a substantial portion of their portfolios in securities that were issued in other countries. During the last decade U.S. investors have held a significant amount of foreign securities with over a trillion dollars invested in foreign assets by 1994. South African institutions have been allowed some freedom to diversify internationally since mid 1995 and individual investors since July 1997. In this paper the potential diversification benefits for South African investors are considered. The stability over time of the correlation structure is investigated and simple ex-ante investment strategies are formulated and evaluated.
\end{abstract}

\section{INTRODUCTION}

Expanding the investment universe to include foreign securities provides for an expanded set of assets whose returns show a low degree of correlation with domestic assets. Foreign securities involve foreign exchange risk, which needs to be taken into account when determining optimal investment strategies. The optimal proportion of foreign assets in a portfolio depends on inter-country correlations of returns as well as the expected returns and variance of return for the various countries with all return data converted into local currency. The literature suggests that past variances and correlations may be useful in predicting the future but that expected returns are unlikely to be strongly correlated to past returns (see e.g. Jorion [5], Eun and Resnick [3], Elton and Gruber [1]). 


\section{http://orion.journals.ac.za/}

The most comprehensive South African study on international diversification is that by Patrick and Ward [9]. The opportunity set considered for international diversification included 20 countries with established economies as well as 15 emerging markets. Markowitz efficient frontiers were used to consider the ex-post benefits of diversification. In order to investigate the benefits from an ex-ante perspective, a portfolio was constructed by placing $3.571 \%$ of capital in each of 26 countries and two sectors of the JSE. In terms of a modified Sharpe ratio (arithmetic average return per standard deviation), this strategy showed approximately a 30\% improvement over the JSE performance during the 19 year period to 1994. Simpler ex-ante strategies of investing in a JSE index and the MSCI world index were also considered over the single 19-year period. It was concluded that over that period diversification benefits would have been obtained for investment levels of up to $55 \%$ in the MSCI world index. It should be noted that each of the ex-ante strategies based on monthly data would have required the investor to rebalance the portfolio once a month, a daunting task especially when 28 sectors are involved! It is also felt that 19 years without intermediate assessment of portfolio performance is not practical in today's volatile markets. In the present study a compromise is made between adequately representing world capital and keeping the number of foreign countries more manageable. Only the four biggest markets representing over $75 \%$ of world capital are included and portfolios are rebalanced every two years to make ex-ante strategies easier to implement.

Risk has many connotations. In the field of investments, risk used to refer to balance sheetsthe more debt, the more risky the asset. Graham \& Dodd [4] defined risk in terms of the difference between the market price and the 'intrinsic value' of an asset. The work of Markowitz [7, 8] and the subsequent development of Modern Portfolio Theory (MPT) and the Standard Capital Asset Pricing Model (CAPM) more clearly defined risk for investments. In MPT investment risk is associated with the variability of rates of return over a time period-the more volatile, the more risky. One common measure of risk is the standard deviation of returns. A fundamental assumption of MVP is that all investors wish to maximise return and minimise risk.

One of the criticisms of MPT arises because it uses volatility as a measure of risk. It is argued that risk is more properly associated with adverse outcomes and that an asymmetric measure of risk such as the semi-variance may be more appropriate. Another measure of downside risk is the Average Maximum Retracement (AMR). The AMR is the average maximum 
percentage retracement experienced at the individual data points over a given period. The maximum retracement at an arbitrary point is the larger of the following two measures:

(i) The maximum percentage retracement from that point to a subsequent equity low,

(ii) The maximum percentage retracement from a previous equity peak.

The AMR therefore truly measures downside risk.

In the case of the two-asset problem discussed in the sequel, the present author has compared both the semi-variance and the AMR with the standard deviation as measures of risk (paper in preparation). Had these alternate measures been used in this study, then the conclusions would not have been materially different.

It should be stated clearly that certain wider issues such as investor liabilities and obligations are not considered in this article. Some would argue that without reference to the liabilities of investors, risk could not even be defined. We assume that investors have undertaken an analysis of these wider issues and have concluded that they have funds available for investment in the equity markets. Our limited aim in this study concerns the risk-adjusted performance of assets invested in the equity markets. We work within the framework of MVP using the standard deviation as the measure of risk.

For a given period of time, each asset has associated with it a certain return and risk. These values may be calculated from historical performance data or analysts may project their expected values into the future. Any combination of assets constitutes a portfolio. Markowitz [8] made the simple observation that every investor prefers more return for less risk. Thus in figure 1, portfolio A is preferred to B (more return for the same risk) and A is preferred to $\mathrm{C}$ (same return for less risk). The correct framework within which to investigate risk and return is that of Modern Portfolio Theory, using in particular the concept of the Efficient Frontier. The latter consists of all those portfolios that offer the most return for a given level of risk. In figure 1 the curve EF denotes the efficient frontier generated by the underlying investment universe consisting of risky assets. The portfolio E will be referred to as the Minimum Variance Portfolio (MVP).

Every investor would prefer to be invested along curve EF; the particular portfolio chosen will depend on the individual risk profile. In the case where a risk-free (zero volatility) asset such as a bank fixed deposit is introduced, a single optimal risky portfolio $\mathrm{T}$ exists. Any 
combination of the risk-free asset $R_{f}$ with a risky asset $\mathrm{X}$ can be shown to lie on the straight line joining $R_{f}$ to $\mathrm{X}$. In combining $R_{f}$ with the efficient frontier EF determined by all risky assets, it is clear that the new efficient frontier becomes the tangent line from $R_{f}$ to T. For any risk level up to and including that of $\mathrm{T}$, any investor, regardless of risk profile, will combine the optimal risky portfolio $\mathrm{T}$ with $R_{f}$ if no borrowing is allowed. For higher risk levels, efficient portfolios between $\mathrm{T}$ and $\mathrm{F}$ could be used. The construction of the Efficient Frontier is described in the appendix.

Figure 1: The Efficient Frontier

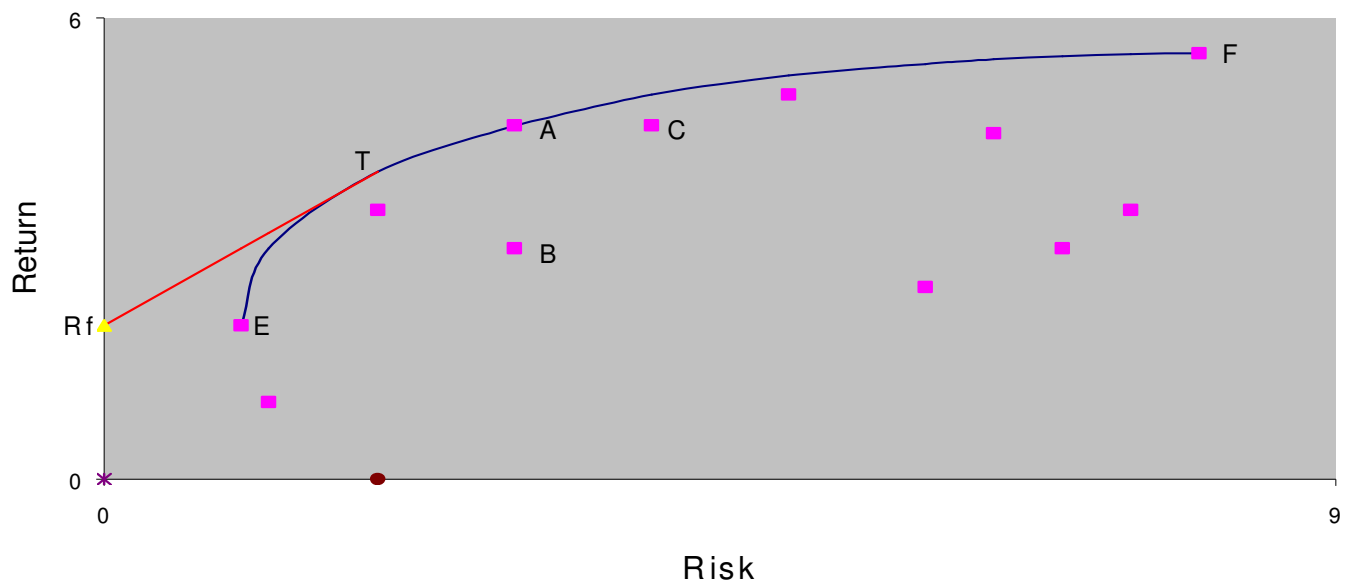

A necessary condition for risk reduction is that correlation coefficients between various assets should be low. Figure 2 illustrates this point by assuming various correlation structures between two assets $\mathrm{A}$ and $\mathrm{B}$ with given return and risk parameters as shown. The average correlation coefficient between two general equity unit trusts in South Africa is of the order of 0.9. This figure was obtained from an analysis of all South African general equity unit trusts with at least a ten-year history to July 1997. On the other hand the correlation coefficient between the JSE and the world market, as measured by the MSCI world index (defined in section 3 below), was 0.21 during the period 1973-1997. It is clear that the locally well diversified unit trust investor who desires significant risk reduction should seriously consider diversifying internationally to find unit trusts that are weakly correlated with the local assets. 
Figure 2: Correlation and Risk

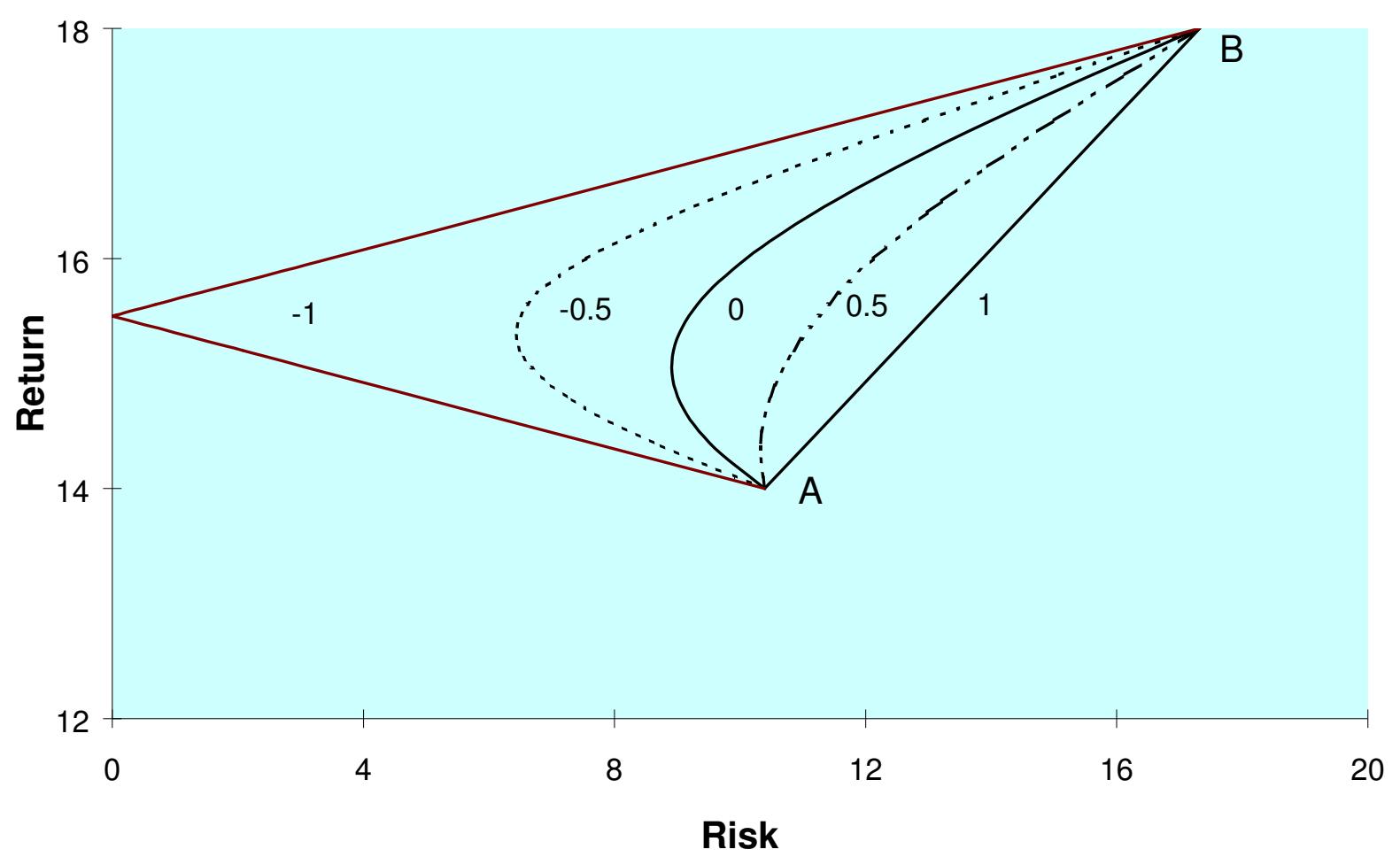

The diversification benefits for a passive South African investor will be investigated. Such an investor is willing to buy and hold assets for a period of several years, without changing the portfolio. In the first instance it will be assumed that a portion of the portfolio is invested in the world market and the rest on the Johannesburg Stock Exchange. We will use the benchmark MSCI world index, computed by Morgan Stanley Capital International, as a proxy for the world market and the JSE All Share Index as a proxy for the South African market.

Secondly portfolios consisting of South African assets and those of the big four capital markets, namely the U.S.A, the U.K., Japan and Germany will be considered. The proxies used for these markets with their abbreviations are listed in table 1 below. 
6

http://orion.journals.ac.za/

\begin{tabular}{ccc}
\hline Market & Proxy & Abbreviation \\
\hline South Africa & JSE All Share Index & JSE \\
Germany & Frankfurt DAX 30 & DAX \\
Japan & Tokyo Nikkei 225 & Nikkei \\
U.S.A. & Standard \& Poor's 500 & SP500 \\
United Kingdom & London FTSE 100 & FTSE \\
\hline
\end{tabular}

Table 1. Market proxies

In 1992 these four foreign markets constituted around $77.5 \%$ of total world equity markets (Elton \& Gruber [1], p262) so that substantial international diversification should be possible. In view of the stated objective of testing some simple investment strategies which could be implemented in practice, it was decided to keep the number of foreign markets to a minimum. Because South African investors are locally exposed to an emerging market, no attempt was made to enlarge the exposure to other emerging markets.

For the world market as well as for each of the four major international markets and corresponding to various assumed returns on the local market, the minimum Rand returns necessary are calculated to make diversification worthwhile. These preliminary results, based on the assumption of a reasonably constant correlation structure, confirm that international diversification should be worthwhile for the SA investor.

Results based on data from 1973-1997 indicate that the Minimum Variance Portfolio constructed from the JSE all share index and the MSCI world index had similar returns to that of the South African market (all returns in Rand terms) but with substantially reduced risk.

A sensitivity analysis of parameters shows that the portfolio mix of the MVP, determined by the correlation structure of the JSE and MSCI, is relatively insensitive to small changes in the correlation coefficients and variances of the two markets. This suggests an investment strategy where historically optimal proportions from the immediate past period could be used as an investment strategy for the next period. The success of this strategy is investigated by back testing. Rebalancing of portfolios is done every two years. 
The investment strategies investigated are unlikely to match historical optimal portfolio performance due to the time variation of the correlation structure. This variation is more fully investigated in the case of the two-asset portfolio.

An investigation of the historical portfolio performance that could have been obtained by a passive South African investor who distributed assets amongst the local market and the four big capital markets is then undertaken. Results indicate that potentially large gains from diversification are possible. In order to investigate how much of this potential gain could be realised in practice, some simple investment strategies are evaluated. Due to the lack of intertemporal stability of the inter-country correlation structure, results show that it is unlikely that these ex-ante strategies will substantially outperform the simple two-asset portfolios described earlier on.

During times when world events dominate local news, correlation coefficients may increase. Dominance of world events is often associated with volatile markets, e.g. the oil crises of 1974 and the world stock market crashes of 1987 and 1997. Longin and Solnik [6] confirmed this observation from a United States point of view by using monthly data for the period 1960-1990. They also demonstrated a clear link between the U.S. stock market risk and its average correlation coefficient with other major stock markets. We investigate this riskcorrelation-coefficient relationship form a South African perspective.

\section{MINIMUM RETURN EXPECTATIONS FOR DIVERSIFICATION BENEFITS}

Most of the diversification literature agrees that historical data predicts risk better than return (see e.g. Jorion [5], Eun and Resnick [3], Elton and Gruber [1]). Assume initially that this is the case for South African securities and accept the historical risk and correlation structure from an immediate past period as a reasonable predictor for the future. It is then possible, for any assumed return on the South African market, to solve for the minimum Rand return necessary on any foreign market, to make that market attractive from a South African viewpoint. Following the method of Elton, Gruber and Rentzler [2], it would pay to hold assets of foreign country $\mathrm{X}$ as long as

$$
\frac{\overline{R_{X}}-R_{f}}{\sigma_{X}}>\frac{\overline{R_{S A}}-R_{f}}{\sigma_{S A}} \rho_{X . S A}
$$

where 
$\overline{R_{X}} \quad$ is the expected return on the foreign market in Rands

$\overline{R_{S A}} \quad$ is the expected return on the South African market

$R_{f} \quad$ is the risk-free rate of interest

$\sigma_{X} \quad$ is the standard deviation of the foreign returns in Rands

$\sigma_{S A}$ is the standard deviation of the S.A market returns

$\rho_{X . S A}$ is the correlation coefficient between the two sets of returns

Returns, risk and correlation coefficients were calculated over the period June 1989 to June 1997 using monthly data. In all cases dividends were not included as this information was not available. Annualised return and risk $^{1}$ figures are shown. The risk-free rate of $8.41 \%$ a year is based on the average annual BA rate of $14.76 \%$ during the above period adjusted for marginal tax at 43\%. Various returns were assumed for the South African market. For interest's sake, these are based on certain historical returns such as the long term rate achieved from 1960 to 1997, the return over the most recent 15 year period, a high hypothetical return of $30 \%$ and a low return of $7.86 \%$ which was the return during the 1996 calendar year. The last four columns of table 2 indicate the minimum Rand returns required on the foreign markets corresponding to the above four returns on the local market. It is clear that international diversification may be worthwhile even if foreign Rand returns considerably lower than South African ones are obtained.

\footnotetext{
${ }^{1}$ The annualised risk is taken as $\sqrt{12}$ times the monthly risk
} 


\begin{tabular}{|l|c|c|c|c|c|c|}
\hline \multicolumn{2}{|c|}{ Correlation Structure } & \multicolumn{3}{c|}{ SA Returns } \\
\cline { 5 - 7 } & $1960+$ & $1982+$ & Hypoth & 1996 \\
\cline { 5 - 7 } & $\begin{array}{l}\text { Std } \\
\text { Mev }\end{array}$ & $\begin{array}{l}\text { Correlation } \\
\text { with SA }\end{array}$ & 13.52 & 20.53 & 30.00 & 7.86 \\
\hline World (MSCI) & 13.5 & 0.28 & 9.62 & 11.28 & 13.53 & 8.28 \\
\hline U.S. (SP500) & 13.9 & 0.24 & 9.44 & 10.86 & 12.77 & 8.30 \\
\hline U.K. (FTSE) & 16.0 & 0.31 & 9.96 & 12.08 & 14.96 & 8.25 \\
\hline Germany (DAX) & 17.4 & 0.40 & 10.63 & 13.67 & 17.78 & 8.17 \\
\hline Japan (Nikkei) & 27.7 & 0.23 & 10.42 & 13.17 & 16.90 & 8.20 \\
\hline
\end{tabular}

Table 2. Minimum Rand returns required for diversification benefits

The foreign Rand return $R_{X}$ has two components, a home return $r_{h}$ in the foreign currency and a foreign exchange one $r_{x}$. From the equation $\left(1+R_{X}\right)=\left(1+r_{h}\right)\left(1+r_{x}\right)$, it follows that $R_{X} \approx r_{h}+r_{x}$. The Rand has been depreciating relative to the other currencies at approximately $8 \%$ per annum. If one assumes that the Rand is likely to depreciate at $8 \%$ during the next forecast period and that the local market is to return $13.52 \%$, then a return of approximately $2 \%[(9.96-8) \%]$ is required on the U.K. market to justify diversification into that market.

These simple preliminary results indicate that substantial benefits could derive from international diversification and that a fuller analysis is justified.

\section{SOUTH AFRICA AND THE WORLD MARKET}

The characteristics of a portfolio consisting of the South African and World markets are investigated next. The JSE all share index and the MSCI world index are used as proxies for these two markets and returns, standard deviations and correlation coefficients are calculated by using monthly data over various periods. All returns were converted to South African Rands at the prevailing exchange rates before calculation of the standard deviations and 
correlation coefficients. Morgan Stanley Capital International computes the MSCI world index. It is a market-weighted index with each stock's proportion in the index determined by its market value divided by the total market value of all stocks. In practice the index includes securities representing approximately $60 \%$ of the total market value of each country. Table 3 below lists the Rand return characteristics of the two markets over various time intervals. Calculations are based on an analysis of monthly data but in the table we show the annual geometric return generated as well as annualised risk figures. The last column shows the percentage investment in the South African market that yielded the Minimum Variance Portfolio in each case.

\begin{tabular}{l|cccccc}
\hline Period & $\begin{array}{c}\text { Std } \\
\text { Dev } \\
\text { JSE }\end{array}$ & $\begin{array}{c}\text { Return } \\
\text { JSE }\end{array}$ & $\begin{array}{c}\text { Std Dev } \\
\text { MSCI }\end{array}$ & $\begin{array}{c}\text { Return } \\
\text { MSCI }\end{array}$ & $\begin{array}{c}\text { Correlation } \\
\text { Coefficient }\end{array}$ & $\begin{array}{c}\text { JSE \% } \\
\text { in } \\
\text { MVP }\end{array}$ \\
\hline May89-Apr97 & 16.5 & 14.1 & 13.6 & 13.9 & 0.28 & 37 \\
May81-Apr89 & 25.0 & 19.9 & 22.8 & 31.8 & 0.16 & 45 \\
May73-Apr81 & 25.8 & 15.7 & 15.3 & 6.1 & 0.24 & 20 \\
\hline May81-Apr97 & 21.2 & 17.0 & 18.9 & 22.9 & 0.20 & 43 \\
May73-Apr89 & 25.4 & 17.8 & 19.7 & 19.0 & 0.19 & 35 \\
\hline & & & & & & 0.21 \\
May73-Apr97 & 22.8 & 16.5 & 17.9 & 17.3 & & 35 \\
\hline
\end{tabular}

Table 3. South Africa and the World Market 1973-1997

Over the 24 year period from May 1973-April 1997, the returns on the two markets were similar but figure 3 below illustrates that substantial risk reduction would have been attained if investment funds had been split between the two markets. The point marked 'JSE' shows the performance of a portfolio consisting of $100 \%$ invested in the JSE and $0 \%$ in the MSCI. Each successive point encountered in a clockwise direction (except for the MVP) reduces the JSE portion by $10 \%$ and adds that to the MSCI portion. 
Figure 3: Efficient Frontier 73-97

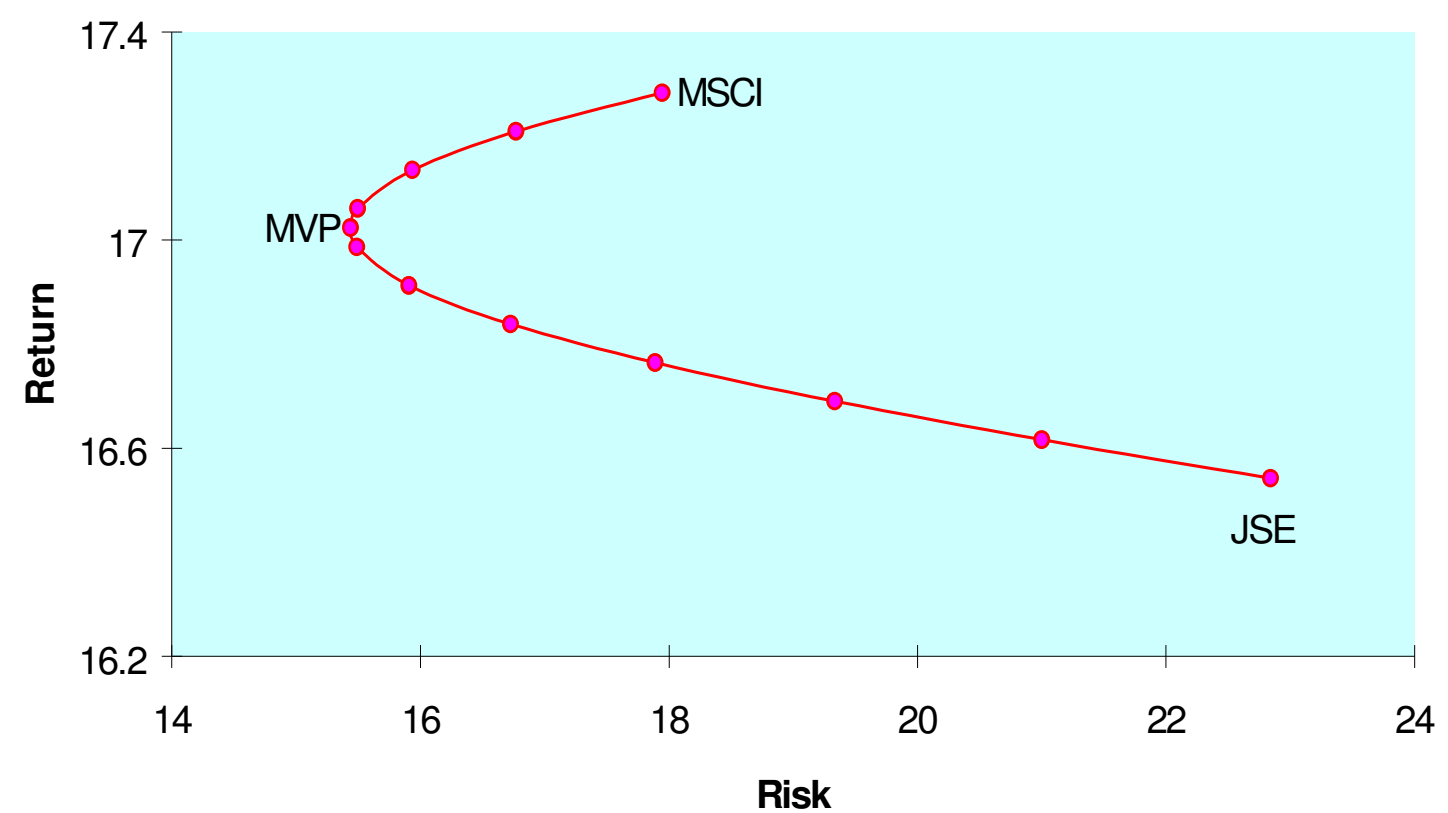

Jorion [5] asserted that if ex-post sample means are used for the estimation of future returns, that assumption then forms the greater part of estimation risk inherent in the development of future international portfolios. He suggested that in order to minimize the impact of this particular form of estimation risk, future portfolio selection should be based more on the MVP since sample estimates of the correlation structure were more stable. In the case of the two-asset problem under consideration, the MVP mix is independent of the actual returns and depends only on the correlation structure. The one investment strategy tested will use a previous period MVP configuration to invest for a future period.

The sensitivity of the MVP mix to the correlation structure is investigated next. Data from the period May 1989 to April 1997 are used. Each parameter is perturbed by $\pm 20 \%$ and the effect observed on the percentage JSE in the MVP as well as on the standard deviation of the MVP. Table 4 below indicates that the MVP is relatively insensitive to these parameter changes with the maximum change in the standard deviation of the MVP less than $15 \%$ in each case. 
http://orion.journals.ac.za/

\begin{tabular}{|l|ccccc|}
\hline Period & $\begin{array}{c}\text { Std dev } \\
\text { JSE }\end{array}$ & $\begin{array}{c}\text { Std dev } \\
\text { MSCI }\end{array}$ & $\begin{array}{c}\text { Correlation } \\
\text { Coefficient }\end{array}$ & $\begin{array}{c}\text { JSE \% } \\
\text { in MVP }\end{array}$ & $\begin{array}{c}\text { Std Dev } \\
\text { MVP }\end{array}$ \\
\hline Standard Parameters & 16.49 & 13.58 & 0.28 & 37 & 11.8 \\
Std dev JSE up 20\% & 19.79 & 13.58 & 0.28 & 26 & 12.5 \\
Std dev JSE down 20\% & 13.19 & 13.58 & 0.28 & 52 & 10.7 \\
Std dev MSCI up 20\% & 16.49 & 16.30 & 0.28 & 49 & 13.1 \\
Std dev MSCI down 20\% & 16.49 & 10.86 & 0.28 & 23 & 10.1 \\
Correlation coeff up 20\% & 16.49 & 13.58 & 0.34 & 36 & 12.1 \\
Correlation coeff down 20\% & 16.49 & 13.58 & 0.23 & 38 & 11.6 \\
\hline
\end{tabular}

Table 4. Model sensitivity to single parameter perturbations

The relative insensitivity of the MVP to changes in the correlation structure suggests the following investment strategy: at the beginning of any investment interval, use the immediate past portfolio configuration of the MVP to invest for the next period. Because the MVP depends only on the correlation structure and not on the actual returns, this does away with the difficult problem of predicting future returns for the markets. In order to back-test the strategy, the fourteen years of monthly data from September 1983 to August 1997 were split into seven disjoint two-year intervals. At the beginning of each two-year period funds were invested in a portfolio that had the same configuration as the historical MVP based on the previous 24 months of data. This portfolio is called the Previous MVP (PMVP). Rebalancing takes place every two years. The performance of the PMVP is compared with various naïve 'fixed proportion' investment strategies. In these strategies a fixed portion of funds is invested in each of the two markets at the beginning of each two-year period with rebalancing taking place every two years. The configuration of the MVP was calculated in the usual manner, which assumes monthly rebalancing. In the table below the historical performances of the MSCI, the JSE and the MVP are compared with the ex-ante investment strategies described above. All computations are based on monthly returns but annualised risk and annualised geometric returns are shown in table 5.

In order to compare risk adjusted performances, we show the annualised geometric return divided by the average annualised standard deviation. In this sense the investment strategies show an improvement of some 70\% over that of the JSE. All strategies outperformed the JSE in 5 out of the 7 sub-periods. 
13

http://orion.journals.ac.za/

\begin{tabular}{|c|c|c|c|c|c|c|c|}
\hline & $M S C I$ & $J S E$ & $M V P$ & $P M V P$ & $\begin{array}{l}30 \% \\
J S E\end{array}$ & $\begin{array}{l}50 \% \\
J S E\end{array}$ & $\begin{array}{l}70 \% \\
J S E\end{array}$ \\
\hline $\begin{array}{l}\text { Geometric } \\
\text { Return }\end{array}$ & 24.56 & 15.42 & 21.42 & 22.77 & 22.85 & 21.31 & 19.37 \\
\hline $\begin{array}{l}\text { Average } \\
\text { Risk }\end{array}$ & 18.46 & 18.74 & 13.98 & 16.59 & 15.82 & 15.21 & 15.68 \\
\hline $\begin{array}{l}\text { Return/ } \\
\text { Ave risk }\end{array}$ & 1.33 & 0.82 & 1.53 & 1.37 & 1.45 & 1.40 & 1.24 \\
\hline
\end{tabular}

Table 5. Performance comparison 1983-1997

Constant fraction investment strategies in the literature usually assume monthly rebalancing of portfolios, which most investors are unlikely to do. It is interesting to compare monthly rebalancing with the two-yearly rebalancing of portfolios advocated in this study. The following table indicates that over the period considered in this article the two methods yield remarkably similar results. It is likely that monthly rebalancing will attract higher transaction costs but these have been ignored in this study.

\begin{tabular}{|l|ccc|ccc|}
\cline { 2 - 7 } \multicolumn{1}{c|}{} & \multicolumn{3}{c|}{ Monthly rebalancing } & \multicolumn{3}{c|}{ Two-yearly rebalancing } \\
\hline & $30 \%$ & $50 \%$ & $70 \%$ & $30 \%$ & $50 \%$ & $70 \%$ \\
& JSE & JSE & JSE & JSE & JSE & JSE \\
\hline Geometric & 22.33 & 20.62 & 18.71 & 22.85 & 21.31 & 19.37 \\
Return & & & & & & \\
Ave Risk & 15.48 & 14.84 & 15.52 & 15.82 & 15.21 & 15.68 \\
Return/ Risk & 1.44 & 1.39 & 1.21 & 1.45 & 1.40 & 1.24 \\
& & & & & & \\
\hline
\end{tabular}

Table 6. Rebalancing of portfolios compared

The sensitivity analysis performed earlier on, as well as the relatively good performance of the PMVP and the constant fraction portfolios, seem to confirm the usually assumed time- 
invariance of the correlation structure. It is informative to investigate the variance of the correlation structure over time more explicitly.

In order to minimize the risk of the two-asset portfolio consisting of the JSE and the MSCI over a given time interval, a fraction $x_{J S E}=\frac{\sigma_{2}^{2}-\sigma_{1} \sigma_{2} \rho}{\sigma_{1}^{2}+\sigma_{2}^{2}-2 \sigma_{1} \sigma_{2} \rho}$ should be invested in the JSE where

$\sigma_{1}=$ standard deviation of returns of the JSE over the given period

$\sigma_{2}=$ standard deviation of returns of the MSCI over the given period

$\rho=$ correlation coefficient between the JSE and the MSCI returns.

Let $\sigma_{1}=a \sigma_{2}$, then $x_{J S E}=\frac{1-a \rho}{a^{2}+1-2 a \rho}$.

During the period of investigation (1983 to 1997), $0<a<2.6$ and $-0.33<\rho<0.56$. An analysis of the above equation shows that for $a<1, x_{J S E}$ increases with $\rho$, whereas if $a>1$, then $x_{\text {JSE }}$ decreases with $\rho$. Furthermore, for a given value of $\rho$, as $a$ increases, $x_{J S E}$ decreases. In figure 4 the relationship between $a, \rho$ and $x_{J S E}$ is shown over time with $a$ measured on the right hand scale. Over the entire period, $x_{J S E}$ exceeded 0.4 only from August 1985 to December 1988 and briefly near June 1992. Contained within these two time intervals are the only sub-periods when $a<1$. Notice how $x_{J S E}$ increased with $\rho$ during these sub-periods, whereas elsewhere it decreases with $\rho$. In general as $\rho$ increases the proportion of the lower risk asset increases in the MVP. The fact that $x_{J S E}<0.4$ more than $75 \%$ of the time partly explains the relatively good performance of portfolios having a bigger fraction invested in the MSCI. 


\section{Figure 4: Fraction JSE in MVP}

(based on 3 yr analysis)

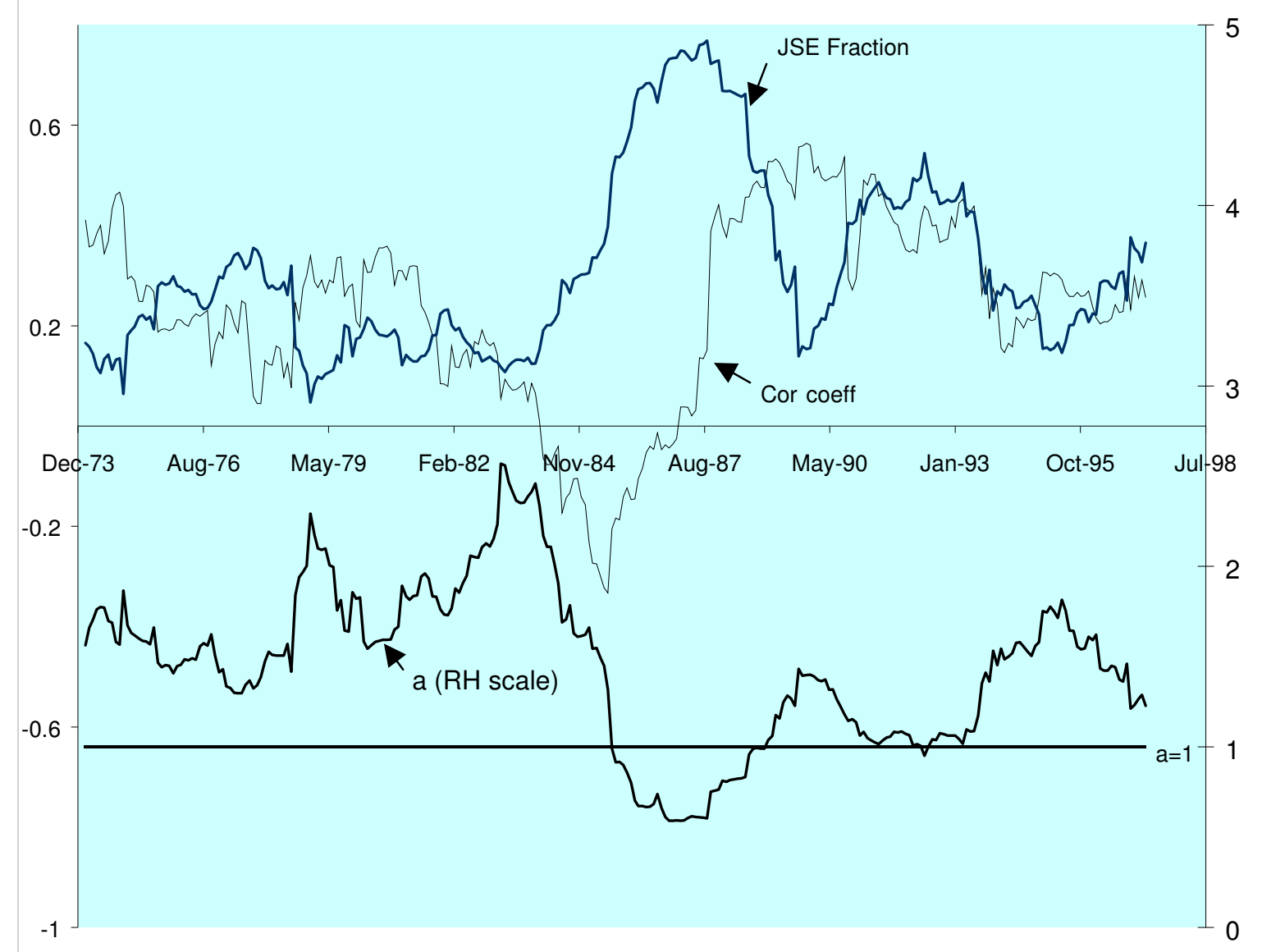

\section{INVESTING IN THE BIG FOUR CAPITAL MARKETS}

When investing in the world market, using the MSCI world index as a proxy, the proportion invested in each market is determined by the size of the market. Given the freedom to decide on the proportions to be invested in the various markets, the corresponding diversification benefits to the South African investor are investigated next. In order to keep the problem manageable and especially to enable the testing of plausible investment strategies, attention is restricted to the big four capital markets. These are the U.S.(38\%), the U.K.(11\%), Japan(24\%) and Germany(4\%) with comparative sizes in 1992 shown in brackets [Morgan Stanley Capital International Perspectives, January 1993]. The South African market is the 10 th largest and constitutes roughly $1 \%$ of the total market.

The table below lists the risk and return characteristics of the various markets derived from monthly performance data over the period July 1989 to July 1997. Average annualised monthly returns and annualised standard deviations are shown in the table. 


\begin{tabular}{l|cccccc}
\hline Market & $\begin{array}{c}\text { Home } \\
\text { Risk }\end{array}$ & $\begin{array}{c}\text { Home } \\
\text { Return }\end{array}$ & $\begin{array}{c}\text { Forex } \\
\text { Risk }\end{array}$ & $\begin{array}{c}\text { Forex } \\
\text { Return }\end{array}$ & $\begin{array}{c}\text { Total } \\
\text { Risk }\end{array}$ & $\begin{array}{c}\text { Total } \\
\text { Return }\end{array}$ \\
\hline South Africa & 16.21 & 15.36 & 0.00 & 0.00 & 16.21 & 15.36 \\
United States & 12.68 & 14.58 & 7.34 & 6.31 & 13.89 & 20.86 \\
United Kingdom & 13.79 & 10.91 & 11.36 & 6.56 & 15.97 & 17.15 \\
Germany & 17.22 & 13.82 & 9.46 & 8.26 & 17.42 & 21.73 \\
Japan & 23.14 & -3.42 & 12.82 & 8.62 & 27.71 & 5.45 \\
\hline
\end{tabular}

Table 7. South Africa and the big four equity markets

It is clear from table 7 that the total risk to the Rand investor of investing in each of the foreign markets is often not significantly higher than just the foreign market risk measured in its own currency. This is a consequence of the low correlation between the forex returns and the market returns in their home currency. This can be seen more precisely as follows: from the relationship $R_{X} \approx r_{h}+r_{x}$ derived earlier on, it follows that $\sigma_{X} \approx \sqrt{\sigma_{h}^{2}+\sigma_{x}^{2}+2 \sigma_{h} \sigma_{x} \rho_{h x}}$, which is very much less than $\sigma_{h}+\sigma_{x}$, provided the correlation coefficient between the home returns and the forex returns is small. Over the period investigated the average correlation coefficient $\rho_{h x}$ had a value of 0.34 .

The Efficient Frontier determined by the above five markets over the period July 1989 to June 1997 was calculated by solving numerous quadratic programming problems (see the appendix). Over this period the average BA rate was $14.8 \%$, so that individual investors would have enjoyed an after tax risk-free rate of return of between $14.8 \%$ and $8.41 \%$, assuming a marginal tax rate of $43 \%$. The Tangent Portfolio corresponding to the case $R_{f}=0.084$ had coordinates $(12.06,20.59)$ in risk-return space and hence significantly outperformed the JSE $(16.21,15.36)$. In terms of return per unit of risk, the two portfolios had ratios of 1.71 and 0.95 respectively.

A parameter sensitivity analysis over the period July 87 to June 97 shows that the Tangent Portfolio was not unduly sensitive to single parameter perturbations. A perturbation of $\pm 20 \%$ in any of the correlation coefficients resulted in changes of the order of $1 \%$ in both the risk 
and return characteristics of the optimal portfolio. Similar perturbations in the standard deviations led to a maximal $6 \%$ change in the risk and $2 \%$ change in the return of the optimal portfolio. Perturbations of $20 \%$ in the market returns resulted in changes in the risk of the optimal portfolio of between $0 \%$ and $6 \%$ and in the return of at most $14 \%$. This suggests an investment strategy where the optimal portfolio structure from the previous period could be used for determining the investment mixture for the following period. In figure 5 the Efficient Frontier generated by the above five markets over the period July 1993 to July 1997 is shown. The performance of the Nikkei is well off the scale. The performance of the portfolios structured according to the previous four-year period optimal and Minimum Variance Portfolios are labelled PTgt and PMVP respectively. The optimal portfolio for the period is based on an after-tax risk-free rate of 7.66 (the BA rate averaged 13.43). For comparison purposes the performance of the MSCI world index is also shown. One can easily visualise the Efficient Frontier generated by just the JSE and the MSCI over this period (cf. figure 3). It seems that there may be some merit in pursuing the PTgt or PMVP strategies.

Figure 5: Efficient Frontier 1993-1997

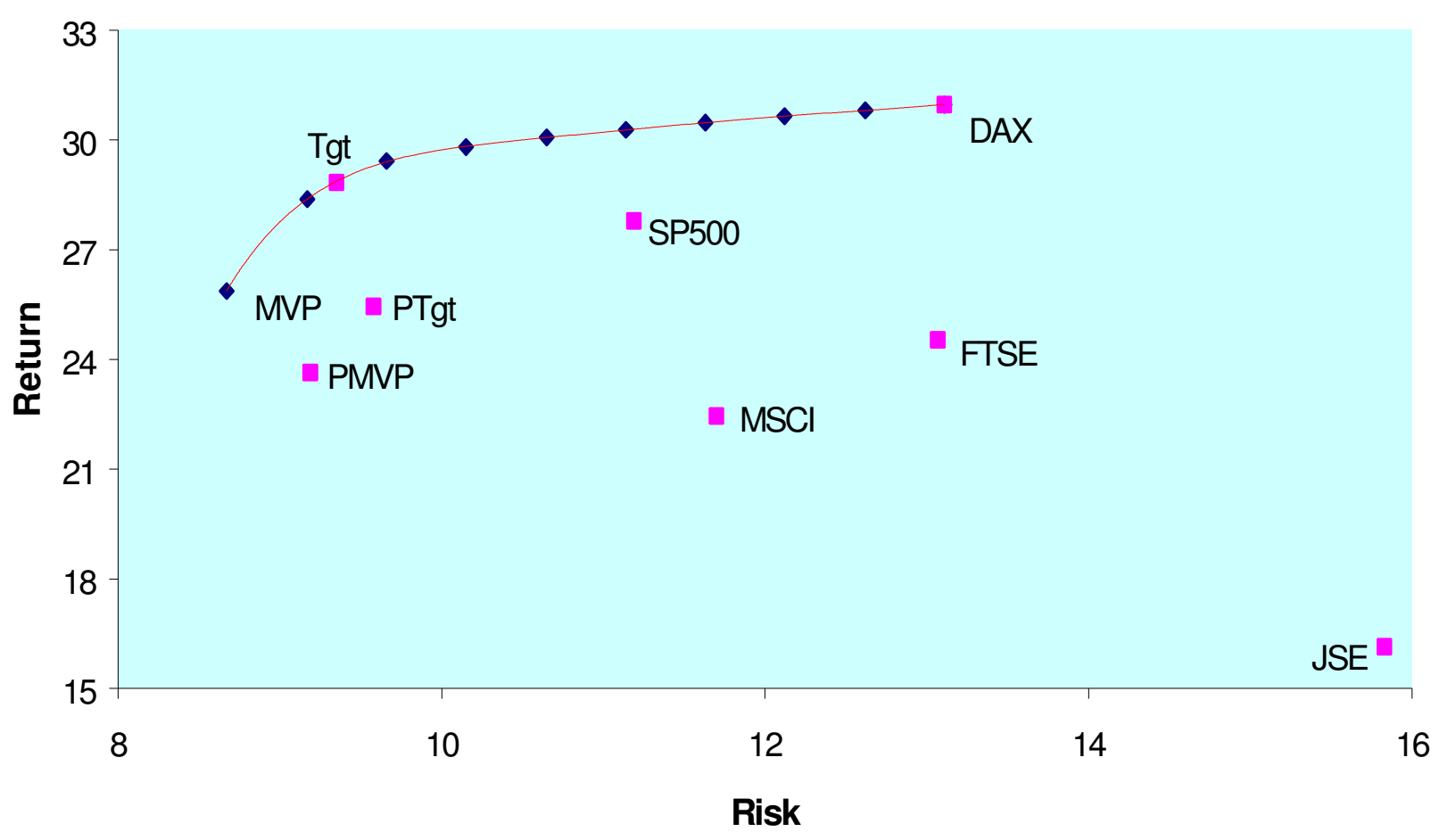


The correlation structure over the two periods is shown in table 8 below. The shaded part below the diagonal of ones gives the correlation coefficients during the first four-year period and that above the main diagonal the coefficients during the second period. The average coefficient changed from 0.40 to 0.29 over the two periods and clearly individual correlation coefficients could not be regarded as approximately constant.

The return and risk on the various markets over the two periods are shown in table 9 below. Generally the returns are significantly higher during the second period and the standard deviations lower.

\begin{tabular}{l|lllll} 
& DAX & FTSE & JSE & Nikkei & SP500 \\
\hline DAX & 1.0 & 0.48 & 0.25 & 0.14 & 0.34 \\
FTSE & 0.61 & 1.0 & 0.19 & 0.39 & 0.61 \\
JSE & 0.48 & 0.39 & 1.0 & 0.11 & 0.02 \\
Nikkei & 0.34 & 0.47 & 0.30 & 1.0 & 0.40 \\
SP500 & 0.34 & 0.57 & 0.27 & 0.23 & 1.0
\end{tabular}

Table 8. Two-period correlation structure comparison

\begin{tabular}{l|lllll}
\hline & DAX & FTSE & JSE & NIKKEI & SP500 \\
\hline First Period & & & & & \\
Risk & 20.8 & 18.3 & 16.5 & 32.5 & 15.4 \\
Return & 11.8 & 11.2 & 11.6 & -2.0 & 13.7 \\
\hline $\begin{array}{l}\text { Risk-adjusted } \\
\text { performance }\end{array}$ & 0.6 & 0.6 & 0.7 & $*$ & 0.9 \\
\hline $\begin{array}{l}\text { Second Period } \\
\text { Risk }\end{array}$ & 13.1 & 13.1 & 15.8 & 24.3 & 11.2 \\
$\quad$ Return & 31.0 & 24.5 & 16.1 & 7.1 & 27.8 \\
Risk-adjusted & 2.4 & 1.9 & 1.0 & 0.3 & 2.5 \\
performance & & & & & \\
\hline
\end{tabular}

Table 9. Two-period performance comparison

It is meaningless to associate a Sharpe ratio with negative returns 
In table 10 below, the performance of portfolios based on the configurations of the previous period minimum variance and the previous period Tangent Portfolio can be compared with the historical performance of the Minimum Variance Portfolio and the Tangent Portfolio. It is generally true that minimum variance portfolios are well diversified, whereas optimal portfolios need not be. The portfolio configurations are shown in the lower part of the table.

\begin{tabular}{l|llll}
\hline & $P M V P$ & $P T g t$ & $M V P$ & $T g t$ \\
\hline Portfolio Risk & 9.2 & 9.6 & 8.6 & 9.4 \\
Portfolio Return & 23.6 & 25.4 & 25.9 & 28.8 \\
\hline Risk-adj. Return & 2.6 & 2.6 & 3.0 & 3.1 \\
\hline DAX & 6.2 & 0.0 & 25.1 & 43.6 \\
FTSE & 4.8 & 0.0 & 0.0 & 0.0 \\
JSE & 39.3 & 20.1 & 23.2 & 3.0 \\
Nikkei & 1.1 & 0.0 & 0.0 & 0.0 \\
SP500 & 48.6 & 79.9 & 51.7 & 53.4 \\
\hline
\end{tabular}

Table 10. Single period performance based on previous portfolio configurations

The two investment strategies returned impressive performances over the above test period. A more thorough back-testing of the above strategies was then carried out. Fourteen years of data from September 1983 to August 1997, split into seven disjoint two-year periods, were analysed. At any given time the immediate past portfolio structure of the MVP or the Tangent Portfolio was used to invest for the next two-year period. Calculations are based on an analysis of monthly return data converted to Rands. The annualised average geometric returns and annualised risk figures are shown in table 11. In order to compare risk adjusted performances, we show the annualised geometric return divided by the average annualised standard deviation. A comparison is also made with a naïve strategy where $20 \%$ of funds is invested in each market throughout the fourteen years with rebalancing taking place every two years.

The historical results in the first seven columns show the significant potential for diversification gains to the South African investor. Each of the three investment strategies 
tested performed better than the JSE but fall far short of the historical optimal portfolio performance. Using the risk adjusted measure, the previous MVP outperformed three of the five individual markets and the previous Tangent Portfolio outperformed two markets. The naïve strategy showed good diversification benefits and outperformed all the individual markets. All three strategies did better than the JSE in five of the seven sub-periods and also over the entire period.

\begin{tabular}{l|cccccccccc}
\hline & U.S. & Ger & U.K. & S.A & Jap & Tgt & MVP & $\begin{array}{c}\text { Prev } \\
\text { MVP }\end{array}$ & $\begin{array}{c}\text { Prev } \\
\text { Tgt }\end{array}$ & Naive \\
\hline $\begin{array}{l}\text { Geometric } \\
\text { Return }\end{array}$ & 24.9 & 28.6 & 24.4 & 15.4 & 22.0 & 33.2 & 23.5 & 22.0 & 22.3 & 24.9 \\
Average Risk & 19.2 & 23.8 & 22.4 & 18.7 & 28.6 & 15.6 & 12.2 & 18.8 & 22.4 & 16.9 \\
Return/Risk & 1.19 & 1.20 & 1.09 & 0.82 & 0.77 & 2.13 & 1.93 & 1.17 & 0.99 & 1.48 \\
\hline
\end{tabular}

Table 11. Risk-adjusted portfolio performance 1983-1997

Compared with the two-portfolio problem, where investments are in the world market and the JSE, the potential gains are far bigger in the study above. Realising these gains is not easy and the risk-adjusted returns of the PMVP and PTgt portfolio strategies are worse than that obtained in the two-portfolio case. Because these two policies are unattractive, two-yearly rebalancing was not investigated.

The underperformance of the PMVP and PTgt investment strategies, compared with the historical efficient portfolios, results from the fact that the correlation structure is more variable form one period to the next than the single-period sensitivity analysis indicated. What is more disturbing is that correlations between different markets seem to increase with increasing volatility. This has been observed for the U.S. market by Longin and Solnik [6]. We illustrate the relationship between JSE risk and its correlation with the four big markets. The same fourteen years of monthly data were used and risk was estimated as the standard deviation (annualised) over two-year subintervals. The average correlation coefficient between the JSE and the other markets over the subintervals was used. The link between risk and correlation is evident from figure 6. 
Figure 6: JSE risk vs correlation

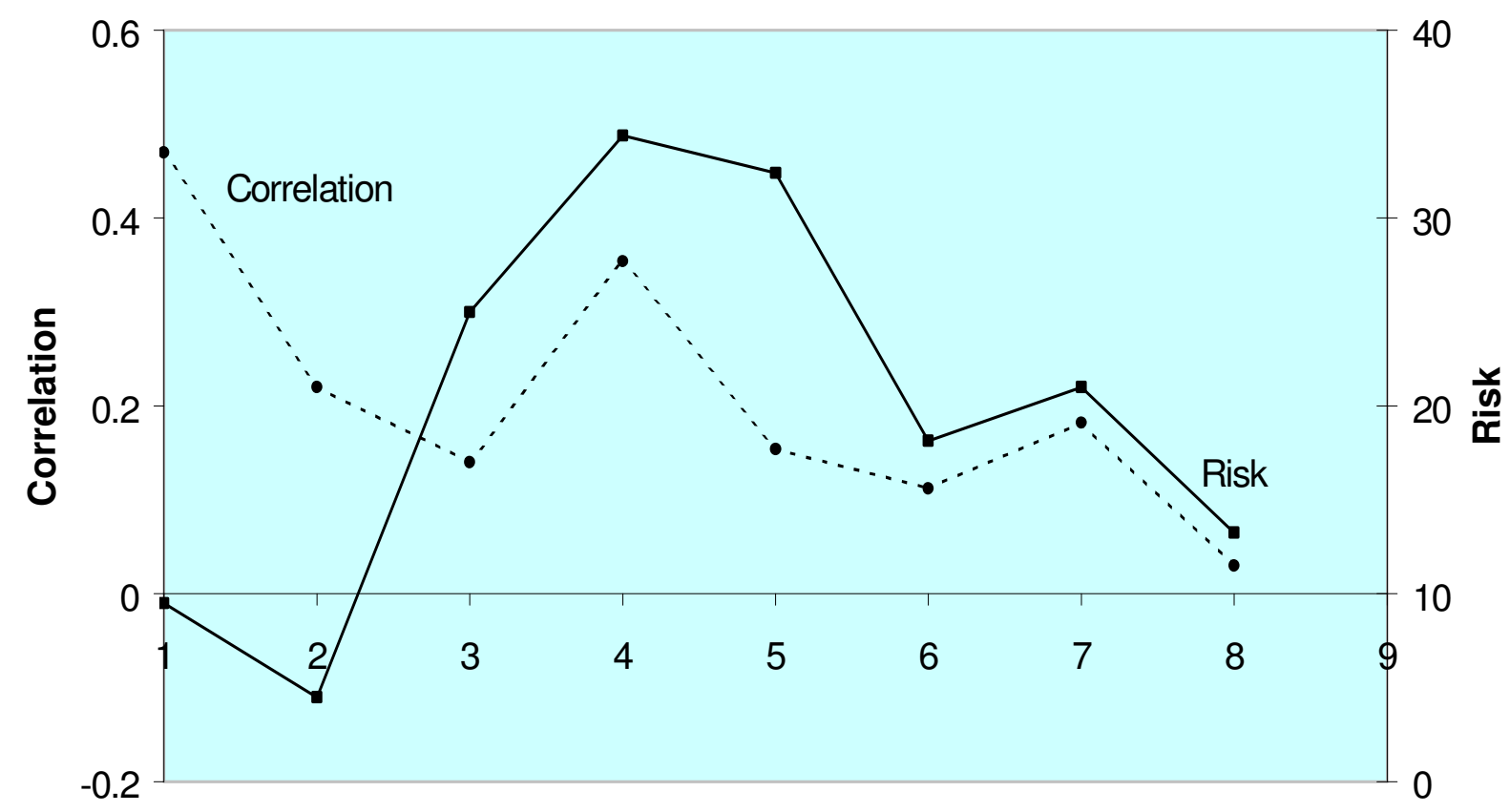

Seven two-year periods: Aug 83-97

\section{CONCLUSION}

The purpose of this article was to investigate the potential benefits of international diversification for South African investors. Over the periods investigated, historical evidence demonstrates potentially significant gains in risk-adjusted performance for the South African investor who diversifies internationally. This performance gain is largely due to a lowering in the portfolio risk made possible by the generally low correlation between international assets.

When investing in foreign assets, currency risk has to be taken into account. Because of the low correlation between the foreign exchange returns and the foreign domestic market returns, the additional risk introduced is small.

It was the purpose of this article to test some simple ex-ante investment strategies. In the case of the two-asset problem, investment strategies based on fixed fractions of between $50 \%$ and $70 \%$ invested in the MSCI, outperformed the JSE by at least $70 \%$ in risk-adjusted terms. The investment strategy based on the previous Minimum Variance Portfolio performed similarly in the two-asset case. In the case where the major equity markets are available for investment, a well-diversified portfolio with $20 \%$ invested in each of the four major markets and the JSE, 
performed $80 \%$ better than the JSE in risk-adjusted terms. In all the above, rebalancing of portfolios occurred only every two years.

The relatively good Rand returns obtained from international diversification resulted from the particular set of circumstances in which South Africa found itself during the period of this study and which caused the Rand to depreciate against most major currencies. Future returns will depend on future movements in the exchange rates. On the other hand, the risk reduction has more theoretical underpinning as shown in this article.

Correlation coefficients and standard deviations are not constant over time and ex-ante investment strategies are unlikely to match the historic performance of efficient portfolios. It was further shown that the correlation between the JSE and the big four capital markets tends to increase at times when the JSE risk is increasing. This link between correlation and risk is unfortunate but does not in any way negate the benefits of international diversification.

In this article only equity market investments were considered. By introducing investments in international bonds, foreign cash and gold into an international portfolio, risk could be further reduced.

At the time of writing, South African investors have been slow in making use of the foreign allowance. This is perhaps natural as the unknown foreign markets are perceived to be risky by those unfamiliar with them. It is not however a rational investment approach. International diversification allows the reduction of national risk and the inclusion of foreign assets will reduce the total portfolio risk due to the low correlation between international markets.

\section{REFERENCES}

[1] E.J. ELTON and M.J. GRUBER, Modern Portfolio Theory and Investment Analysis, $5^{\text {th }}$ ed., John Wiley \& Sons, New York (1995).

[2] E.J. ELTON, M.J. GRUBER and J. RENTZLER, Professionally managed, publicly traded community funds, The Journal of Business, 60, 175-199 (1987).

[3] C. EUN and B. RESNICK, Exchange rate uncertainty, forward contracts and international portfolio selection, Journal of Finance, 39, 1311-1324 (1984).

[4] B. GRAHAM, D. DODD and S. COTTLE, Security Analysis Principles and Techniques, $4^{\text {th }}$ ed., McGraw-Hill, New York (1962). 
http://orion.journals.ac.za/

[5] P. JORION, International diversification with estimation risk, Journal of Business, 58, 259-278 (1985).

[6] F. LONGIN and B. SOLNIK, Is the international correlation of equity returns constant: 1960-1990?, Journal of International Money and Finance, 14, 3-26 (1995).

[7] H. MARKOWITZ, Portfolio selection, Journal of Finance, 7, 77-91 (1952).

[8] H. MARKOWITZ, Portfolio Selection: Efficient Diversification of Investments, John Wiley \& Sons, New York (1959).

[9] I.D. PATRICK and M.J.D. WARD, International Diversification and the Portfolio Investor, Transactions of the Actuarial Society of South Africa, 11, 334-417 (1996).

\section{APPENDIX}

Consider a portfolio comprising $\mathrm{m}$ assets held over a time interval of $\mathrm{n}$ periods. Suppose a fraction $x_{i}$ is invested in the $i$ th asset and denote the return on the $i$ th asset in period $t$ by $R_{i t}$. The expected portfolio return $\overline{R_{p}}$ and portfolio risk $\sigma_{p}$ are then given by

$$
\bar{R}_{p}=\sum_{i=1}^{m} x_{i} \bar{R}_{i}
$$

and

$$
\sigma_{p}=\sqrt{\sum_{j=1}^{m} \sum_{k=1}^{m} x_{j} x_{k} \rho_{j k} \sigma_{j} \sigma_{k}}
$$

where

$$
\begin{gathered}
\bar{R}_{i}=\frac{1}{n} \sum_{t=1}^{n} R_{i t} \quad(\text { arithmetic mean return) } \\
\sigma_{j}=\sqrt{\frac{1}{n-1} \sum_{t=1}^{n}\left(R_{j t}-\bar{R}_{j}\right)^{2}} \quad \text { (standard deviation of return) } \\
\rho_{j k}=\frac{\sigma_{j k}}{\sigma_{j} \sigma_{k}} \quad \text { (correlation coefficient) } \\
\sigma_{j k}=\frac{1}{n-1} \sum_{t=1}^{n}\left(R_{j t}-\overline{R_{j}}\right)\left(R_{k t}-\overline{R_{k}}\right) \quad \text { (covariance of returns). }
\end{gathered}
$$

The Efficient Frontier determined by a universe of risky assets is obtained as follows. Each efficient portfolio is determined by minimising the risk for a given (feasible) level of return; 
thus to obtain a point on the Efficient Frontier EF (see figure 1), we solve the quadratic programming problem:

$$
\begin{aligned}
\text { Minimise } \sigma_{p} & =\sqrt{\sum_{j=1}^{m} \sum_{k=1}^{m} x_{j} x_{k} \rho_{j k} \sigma_{j} \sigma_{k}} \text { subject to the constraints } \\
\sum_{i=1}^{m} x_{i} & =1, \sum_{i=1}^{m} x_{i} \bar{R}_{i}=\bar{R}_{p}, \quad x_{i} \geq 0(i=1,2, \ldots m)
\end{aligned}
$$

where $\bar{R}_{p}$ is a value between the return on the MVP and the maximum return portfolio. In practice the coordinates of the MVP are obtained by solving the above quadratic programming problem with the middle constraint removed and the Efficient Frontier is then traced out by specifying a sufficient number of portfolio return values between the maximum and minimum.

When a risk-free rate $R_{f}$ is introduced the optimal or Tangent Portfolio is determined by solving the following quadratic programming problem:

$$
\begin{gathered}
\text { Maximise } \frac{\bar{R}_{p}-R_{f}}{\sigma_{p}} \text { subject to the constraints } \\
\sum_{i=1}^{m} x_{i}=1 \text { and } x_{i} \geq 0(i=1,2, \ldots m) .
\end{gathered}
$$

In each case the first constraint simply asks that the fractions of funds invested in the various assets add to one. The last constraint ensures that a positive or zero investment is made in each asset, i.e., no short selling is allowed. 